\title{
Heating Augmentation in Laminar Flow Due to Heat-Shield Cavities on the Project Orion CEV
}

\author{
Brian R. Hollis ${ }^{*}$ \\ NASA Langley Research Center, Hampton, VA, 23681
}

\begin{abstract}
An experimental study has been conducted to assess the effects of compression pad cavities on the aeroheating environment of the Project Orion CEV heat-shield at laminar conditions. Testing was conducted in Mach 6 and Mach 10 perfect-gas wind tunnels to obtain heating measurements on and around the compression pads using global phosphor thermography. Consistent trends in heating augmentation levels were observed in the data and correlations of average and maximum heating at the cavities were formulated in terms of the local boundary-layer parameters and cavity dimensions. Additional heating data from prior testing of Genesis and Mars Science Laboratory models were also examined to extend the parametric range of cavity heating correlations.
\end{abstract}

\section{Nomenclature}

$A F=$ compression pad heating augmentation factor

$\mathrm{C} 1 . . \mathrm{C} 4=$ constants in augmentation factor correlation

$D_{\mathrm{PAD}}=$ compression pad diameter $(\mathrm{m})$

$h=$ heat transfer film coefficient $\left(\mathrm{kg} / \mathrm{m}^{2} / \mathrm{s}\right)$

$h_{F R}=$ Fay-Riddell heating expressed in film coefficient form $\left(\mathrm{kg} / \mathrm{m}^{2} / \mathrm{s}\right)$

$H_{\mathrm{PAD}}=$ compression pad recessed depth $(+)$ or protruding height $(-)(\mathrm{m})$

$H_{0} \quad=$ total enthalpy $(\mathrm{J} / \mathrm{kg})$

$H_{300 K}=$ cold-wall $($ at $300 \mathrm{~K})$ enthalpy $(\mathrm{J} / \mathrm{kg})$

$M_{\infty} \quad=$ free stream Mach number

$M_{e} \quad=$ boundary-layer edge Mach number

$p_{\infty} \quad=$ free stream pressure $(\mathrm{Pa})$

$q=$ heat transfer rate $\left(\mathrm{W} / \mathrm{cm}^{2}\right)$

$q_{F R} \quad=$ Fay-Riddell prediction for stagnation-point heating $\left(\mathrm{W} / \mathrm{cm}^{2}\right)$

$r / R_{B} \quad=$ normalized radial location of pad

$R_{B} \quad=$ maximum vehicle radius $(\mathrm{m})$

$R_{\text {cav }} \quad=$ cavity radius $(\mathrm{m})$

$R_{N} \quad=$ spherical nose cap radius $(\mathrm{m})$

$R_{S} \quad=$ shoulder radius $(\mathrm{m})$

$R e_{\infty} \quad=$ free stream unit Reynolds Number $(1 / \mathrm{m}$ or $1 / \mathrm{ft})$

$\operatorname{Re}_{\theta} \quad=$ boundary-layer momentum thickness Reynolds number

$T_{\infty} \quad=$ free stream temperature $(\mathrm{K})$

$U_{\infty} \quad=$ free stream velocity $(\mathrm{m} / \mathrm{s})$

$x, y, z=$ vehicle geometric coordinate system variables

$\alpha \quad=$ model angle of attack $(\mathrm{deg})$

$\phi \quad=$ model roll angle $(\mathrm{deg})$

$\delta \quad=$ boundary layer height $(\mathrm{m})$

$\rho_{\infty} \quad=$ free stream density $\left(\mathrm{kg} / \mathrm{m}^{3}\right)$

$\theta=$ included half-angle of spherical nose cap (deg)

\section{Background}

The Crew Exploration Vehicle (CEV) concept was defined by NASA's Exploration Systems Architecture Study (Ref. 1). This study was conducted in 2005 to define requirements for crew and cargo launch systems to support lunar and Mars exploration programs as well as access to the International Space Station (ISS). Several versions of the Orion CEV are planned that will provide transportation first to the ISS, then to the moon, and finally to Mars.

\footnotetext{
* Aerospace Engineer, Aerothermodynamics Branch, Senior AIAA Member
} 
The Crew Module of the CEV (Figure 1) has a configuration that is externally similar to the Apollo Command Module - a spherical-segment heat-shield joined by a small toroidal section to a truncated-cone shaped crew compartment. The Orion CEV however, will be considerably larger than Apollo with a maximum heat-shield diameter of $\sim 5 \mathrm{~m}$ (current configuration) vs. $3.912 \mathrm{~m}$ for Apollo. This larger size will allow transport of up to six crew members on International Space Station missions or up to 4 crew members on Lunar missions.
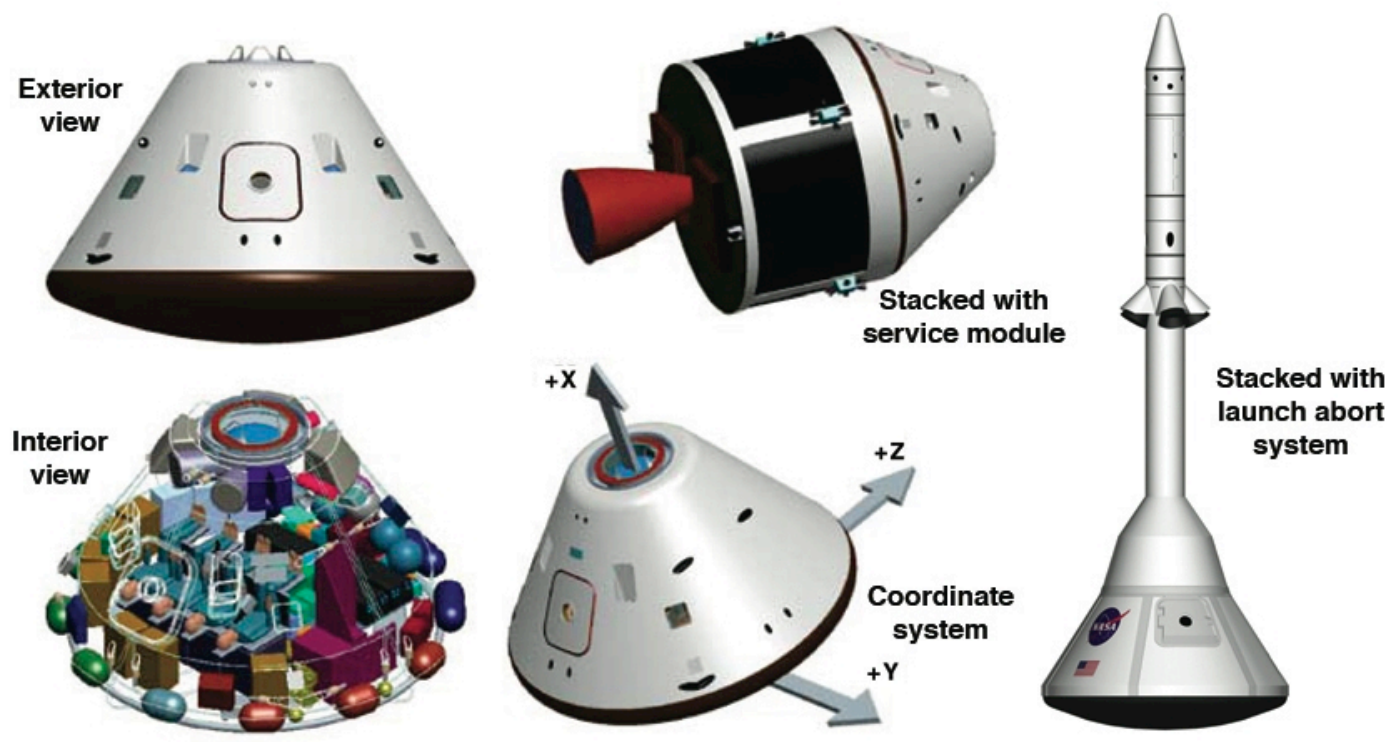

Figure 1. NASA Crew Exploration Vehicle (conceptual artwork)

In a proposed design similar to that of the Apollo capsule, the CEV crew module will be attached to the service module by six compression pad and tie-rod assemblies (Figure 2) spaced at 60-degree increments around the heatshield of the vehicle. In current designs, the heat-shield material is Phenolic Impregnated Carbon Ablator (PICA) and the compression pad material is carbon-phenolic. Because these two materials will ablate at different rates during reentry, the compression pads may be recessed below, or protruding above, the heat-shield at different points along the reentry trajectory. However, a design goal is to ensure that the compression pads do not protrude above the outer-mold line (OML) of the heat-shield until well after peak-heating along the trajectory. As evidenced from examination of recovered Apollo heat-shields (Figure 3) the compression pads, whether recessed or protruding, have the potential to cause large perturbations to heating levels as well as to promote boundary-layer transition.

In order to obtain information for the design of the CEV heat-shield, a parametric investigation of compression pad heating effects has been performed on a generic CEV configuration through testing in the Langley Research Center (LaRC) 20-Inch Mach 6 and 31-Inch Mach 10 Air Tunnels. These tests encompassed only laminar boundary layer conditions upstream of the compression pads; additional testing is planned at transitional and turbulent boundary-layer conditions. In these tests, global heat transfer data on the pads and heat-shield were obtained using the Langley Thermographic Phosphor imaging technique. The two-dimensional image data were then mapped to three-dimensional CAD models of the geometries in order to extract detailed, geometrically-correct information in the vicinity of the pads. Supporting information was obtained through Computational Fluid Dynamics (CFD) predictions for a "smooth-body" (no compression pads) geometry at the wind tunnel test conditions in order to correlate the experimental data and to determine ratios of measured compression pad heating to predicted smooth OML laminar heating.

In addition to the CEV data obtained in the current study, existing data (Refs. 2 - 5) from previous cavity heating studies for the Genesis and Mars Science Laboratory (MSL) programs were also factored into these correlations. For the Genesis mission, a parametric study on cavity heating effects was conducted that helped to define the location and size of the attachment point cavities that were employed on the actual flight vehicle. For the MSL program, a similar, larger, parametric study was conducted. The heating augmentation data obtained in that study provided evidence to support the decision to move the attachment points from the forebody to the aftbody of the entry vehicle where the heating effects will be less severe. 


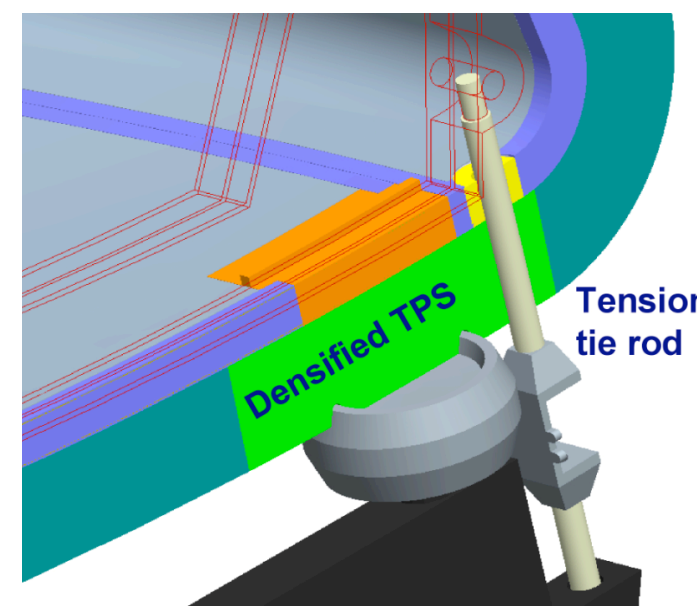

Figure 2. Generic compression pad / tie-rod concept for CEV

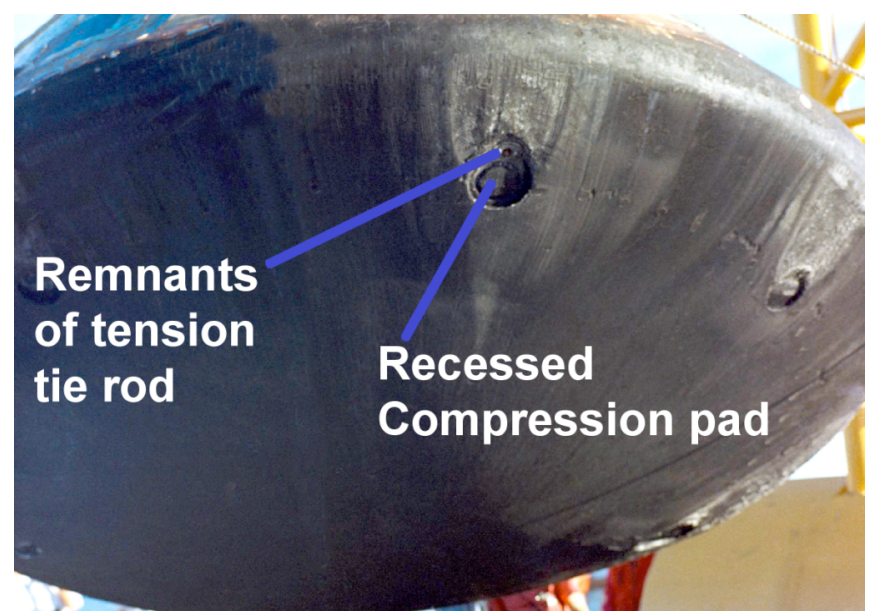

Figure 3. Effects of compression pad heating on Apollo Command Module heat-shield

\section{Experimental Method}

\section{A. Compression Pad Model Design}

Models of the CEV vehicle with both recessed and protruding compression pads were slip-cast in silica-ceramic and coated with a thermographic phosphor compound as per the process discussed in Ref. 6 . The model scale was 0.03556 (based on an assumed $5.00 \mathrm{~m}$ full scale diameter at the time of the model design), which resulted in 0.1778 $\mathrm{m}$ (7-inch) max-diameter models. The model Outer Mold Line (OML) was a generic smooth-body representation based on early Project Orion design cycles. A diagram of the CEV model is given in Figure 4 and model dimensions are listed in Table 1.

Compression pads were added to the smooth OML on each model at 60-deg increments around the circumference of the heat-shield at a radial position of $81 \%$ of the maximum radius. The pad diameter on the models was $0.724 \mathrm{~cm}(0.285$-inch) which represented full-sized pads of 20.32-cm (8-inch) based on geometric (rather than boundary layer height) scaling. Since the ablation/recession response of the pads and surrounding heatshield has not yet been defined and the compression pad design has not yet been finalized, models with two different recessed and protruding cavity depths and heights were tested to obtain a parametric range of data. Each model had three protruding pads and three recessed pads, which allowed for data-gathering on both types of pad at all six locations by performing two wind tunnel runs with the model rotated 180-deg about its axis between runs. In all cases, the pad was modeled as a simple cylindrical geometry either protruding above, or recessed into, the model surface with the cylinder's axis perpendicular to that of the local surface. These pads did not include the tension ties, although data on their effects were documented in Ref. 7. Two CEV configuration models, CEV-1X and CEV$2 \mathrm{X}$, were tested. The $1 \mathrm{X}$ model pad depth was based on a geometric scaling of preliminary estimated values along the trajectory for flight conditions (which have since changed), while the $2 \mathrm{X}$ values were twice those of the $1 \mathrm{X}$ model. The compression pad cavity geometric information is listed in Table 2.

The MSL and Genesis model designs were discussed in Refs. 2 - 5. Both designs included a variety of cavity diameters, depths, and radial locations in order to obtain a wide range of parametric data. Diagrams of the MSL and Genesis models are given in Figure 5 and Figure 6 and dimensions are listed in Table 1. The cavity geometric information for these models is given in Table 2 along with the CEV data (note that all cavity and pad dimensions are for wind tunnel models, not the final flight configurations).

Table 1. Wind Tunnel Model Dimensions

\begin{tabular}{ccccc}
\hline Configuration & $\mathbf{R}_{\mathbf{B}}(\mathbf{m})$ & $\mathbf{R}_{\mathbf{N}} / \mathbf{R}_{\mathbf{B}}$ & $\mathbf{R}_{\mathbf{S}} / \mathbf{R}_{\mathbf{B}}$ & $\boldsymbol{\theta}(\mathbf{d e g})$ \\
\hline CEV & 0.08890 & 2.40 & 0.100 & 23.04 \\
MSL & 0.06350 & 0.50 & 0.050 & 20.00 \\
Genesis & 0.06985 & 0.57 & 0.044 & 30.19 \\
\hline
\end{tabular}




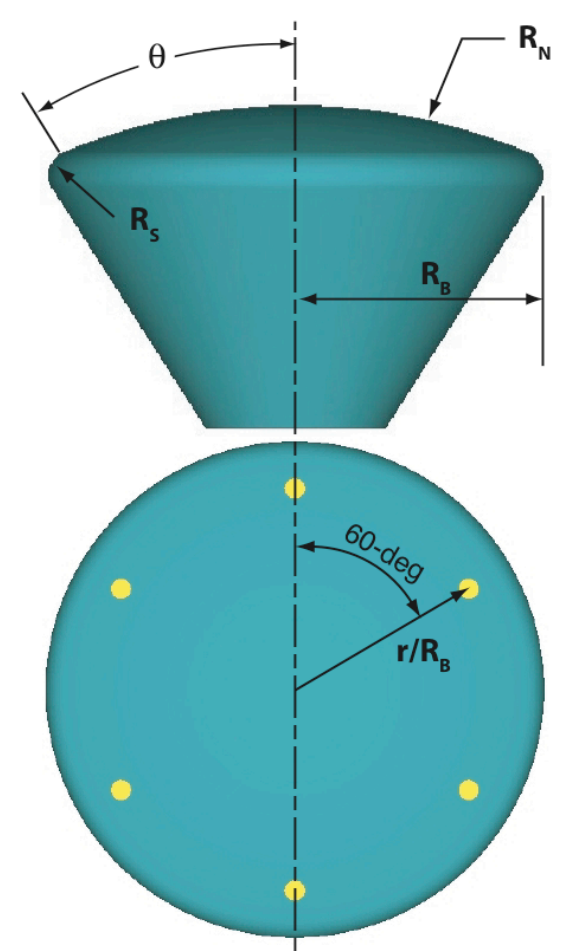

Figure 4. CEV Model

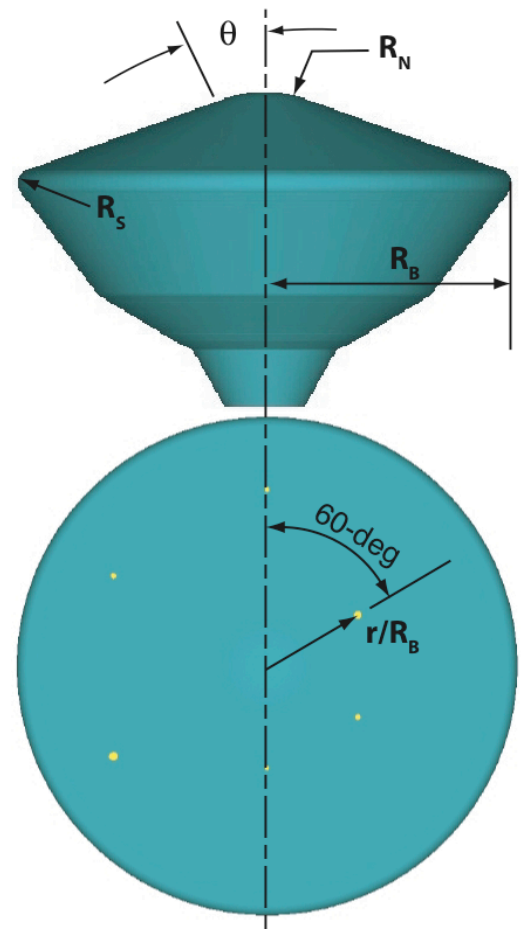

Figure 5. MSL Model

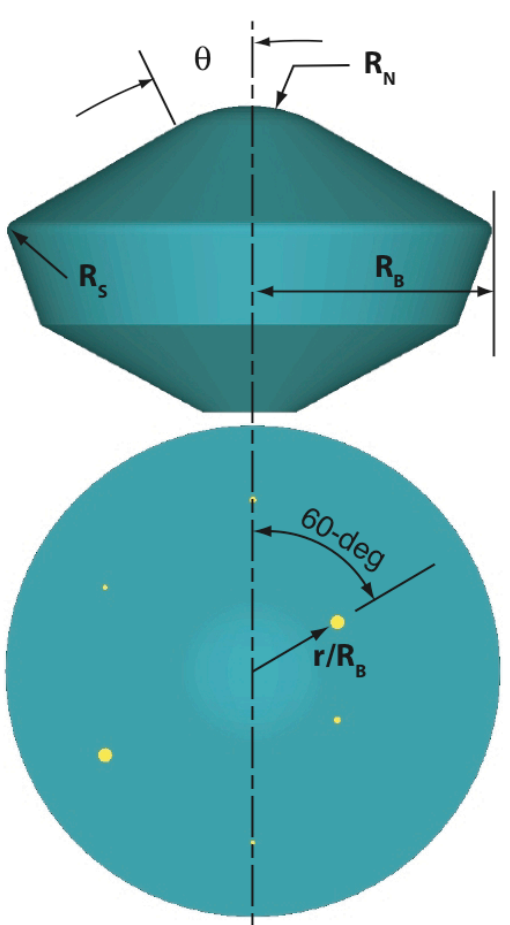

Figure 6. Genesis Model

Table 2. Pad Dimensions (negative depth values are for protruding pads)

\begin{tabular}{|c|c|c|c|c|c|c|c|c|c|c|c|c|c|c|c|}
\hline Model & ad & $\begin{array}{c}\phi \\
\text { (deg) }\end{array}$ & $\mathbf{r} / \mathbf{R}_{\mathbf{B}}$ & $\begin{array}{l}D_{\text {pad }} \\
(\mathbf{c m})\end{array}$ & $\begin{array}{l}\mathbf{H}_{\text {pad }} \\
(\mathrm{cm})\end{array}$ & $\begin{array}{l}D_{\text {pad }} \\
\text { (in) }\end{array}$ & $\begin{array}{l}\mathbf{H}_{\text {pad }} \\
\text { (in) }\end{array}$ & Model & Pad & $\begin{array}{c}\phi \\
(\operatorname{deg})\end{array}$ & $\mathbf{r} / \mathbf{R}_{\mathbf{B}}$ & $\begin{array}{l}D_{\text {pad }} \\
(\mathbf{c m})\end{array}$ & $\begin{array}{l}\mathbf{H}_{\text {pad }} \\
(\mathrm{cm})\end{array}$ & $\begin{array}{l}\text { D }_{\text {pad }} \\
\text { (in) }\end{array}$ & $\begin{array}{c}\mathbf{H}_{\mathrm{pad}} \\
\text { (in) }\end{array}$ \\
\hline \multirow[t]{6}{*}{ CEV-1X } & 1 & 0 & 0.81 & 0.724 & .063500 & 0.2850 & 0.0250 & \multirow[t]{6}{*}{ MSL } & 1 & 0 & 0.70 & 0.218 & 0.067310 & 0.0859 & 0.0265 \\
\hline & 2 & 60 & 0.81 & 0.724 & 0.063500 & 0.2850 & 0.0250 & & 2 & 60 & 0.41 & 0.139 & 0.048514 & 0.0549 & 0.0191 \\
\hline & 3 & 120 & 0.81 & 0.724 & 0.063500 & 0.2850 & 0.0250 & & 3 & 120 & 0.41 & & 0.040894 & 0.0495 & 0.0161 \\
\hline & 4 & 180 & 0.81 & 0.724 & -0.035560 & 0.2850 & -0.0140 & & 4 & 180 & 0.41 & & 0.071374 & & \\
\hline & 5 & 240 & & & -0.035560 & & -0.0140 & & 5 & 240 & 0.70 & & & & 0.0120 \\
\hline & 6 & 300 & 0.81 & 0.724 & -0.035560 & 0.2850 & -0.0140 & & 6 & 300 & 0.70 & 0.109 & 0.029210 & & 0.0115 \\
\hline \multirow[t]{6}{*}{ CEV-2X } & 1 & 0 & 0.81 & 0.724 & 0.127000 & 0.2850 & 0.0500 & \multirow[t]{6}{*}{ Genesis } & 1 & 0 & 0.70 & 0.183 & 0.027940 & 0.0722 & 0.0110 \\
\hline & 2 & 60 & 0.81 & 0.724 & 0.127000 & 0.2850 & 0.0500 & & 2 & 60 & 0.40 & 0.399 & 0.046228 & 0.1569 & 0.0182 \\
\hline & 3 & 120 & 0.81 & 0.724 & 0.127000 & 0.2850 & 0.0500 & & 3 & 120 & 0.40 & 0.200 & 0.046482 & 0.0788 & 0.0183 \\
\hline & 4 & 180 & 0.81 & 0.724 & -0.071120 & 0.2850 & -0.0280 & & 4 & 180 & 0.70 & 0.110 & 0.026670 & 0.0435 & 0.0105 \\
\hline & 5 & 240 & 0.81 & 0.724 & -0.071120 & 0.2850 & -0.0280 & & 5 & 240 & 0.70 & 0.404 & 0.026416 & 0.1591 & 0.0104 \\
\hline & 6 & 300 & 0.81 & 0.724 & -0.071120 & 0.2850 & -0.0280 & & 6 & 300 & 0.70 & 0.149 & 0.039116 & 0.0587 & 0.0154 \\
\hline
\end{tabular}

\section{B. Facility Descriptions and Test Parameters}

\section{NASA LaRC 31-Inch Mach 10 Air Tunnel}

The NASA LaRC 31-Inch Mach 10 Air Tunnel (Figure 7) is a conventional blow-down facility in which heated, dried, and filtered air is used as the test gas; a detailed description of this facility can be found in Ref. 8 . The tunnel has a two-dimensional, contoured nozzle that opens into a 31.0-in. $\times 31.0$-in. $(0.728 \mathrm{~m} \times 0.728 \mathrm{~m})$ test section. The tunnel is equipped with a side-mounted injection system that can transfer a model from the sheltered model box to the tunnel centerline in less than 1 second. Run times of several minutes are possible in this facility, although for aeroheating tests run times of only a few seconds are required. The nominal reservoir conditions of this facility are stagnation pressures of $2.41 \mathrm{MPa}$ to $10.0 \mathrm{MPa}(350 \mathrm{psia}$ to $1450 \mathrm{psia}$ ) with a stagnation temperature of $1000 \mathrm{~K}$ $\left(1800^{\circ} \mathrm{R}\right)$ that produce perfect-gas free stream conditions of Mach 9.7 to 10.0 at unit Reynolds numbers of $0.5 \times 10^{6}$ /ft to $2.0 \times 10^{6} / \mathrm{ft}\left(1.6 \times 10^{6} / \mathrm{m}\right.$ to $\left.6.6 \times 10^{6} / \mathrm{m}\right)$. 
A total of 18 runs were performed in Test 446 in the LaRC 31-Inch Mach 10 Air Tunnel on the CEV 1X pad configuration. The test parameters were: angles of attack $(\alpha)$ of 16-deg, 20-deg, and 24-deg; roll angles $(\phi)$ of 60deg and 240-deg; and free-stream unit Reynolds numbers $\left(R e_{\infty}\right)$ of $0.5 \times 10^{6} / \mathrm{ft}, 1.0 \times 10^{6} / \mathrm{ft}, 1.4 \times 10^{6} / \mathrm{ft}$, and $2.0 \times 10^{6} / \mathrm{ft}$. Nominal conditions for each of the test Reynolds numbers are given in Table 3. Run-to-run variations in conditions were less than $\pm 1 \%$.

\section{NASA LaRC 20-Inch Mach 6 Air Tunnel}

The NASA Langley Research Center 20-Inch Mach 6 Air Tunnel (Figure 8) is a blow-down facility in which heated, dried, and filtered air is used as the test gas; a detailed description of this facility can be found in Ref. 8 . The tunnel has a two-dimensional contoured nozzle that opens into a $20.5 \mathrm{in} . \times 20.0$ in. $(0.52 \mathrm{~m} \times 0.508 \mathrm{~m})$ test section. The tunnel is equipped with a bottom-mounted injection system that can transfer a model from the sheltered model box to the tunnel centerline in less than $0.5 \mathrm{sec}$. Run times of up to 15 minutes are possible in this facility, although for the current aeroheating study run times of only a few seconds were required. The nominal reservoir conditions of this facility produce perfect-gas free-stream flows with Mach numbers between 5.8 and 6.1 and unit Reynolds numbers of $0.5 \times 10^{6} / \mathrm{ft}$ to $7.3 \times 10^{6} / \mathrm{ft}\left(1.64 \times 10^{6} / \mathrm{m}\right.$ to $\left.23.3 \times 10^{6} / \mathrm{m}\right)$.

A total of 39 runs were performed in Test 6946 in the LaRC 20-Inch Mach 6 Air Tunnel on the CEV 1X and 2X compression pad models. The test parameters were: angles-of-attack $(\alpha)$ of 16-deg, 20-deg, and 24-deg; roll angles $(\phi)$ of $0-\mathrm{deg}$ and $180-\mathrm{deg}$; and free-stream unit Reynolds numbers $\left(R e_{\infty}\right)$ of $2.1 \times 10^{6} / \mathrm{ft}, 5.1 \times 10^{6} / \mathrm{ft}$, and $7.5 \times 10^{6} / \mathrm{ft}$. Nominal conditions for each of the test Reynolds numbers are given in Table 4. Run-to-run variations in conditions were less than $\pm 1 \%$.

More than 250 runs were performed on the MSL model and Genesis models in the LaRC 20-Inch Mach 6 Air Tunnel tests. Test parameters were: angles of attack of 0-deg to 20-deg; roll angles $(\phi)$ of 0-deg to 300-deg; and free-stream unit Reynolds numbers $\left(R e_{\infty}\right)$ of $2.1 \times 10^{6} / \mathrm{ft}$ to $5.8 \times 10^{6} / \mathrm{ft}$. Free stream conditions for those runs have been given in Refs. 2 - 5 .

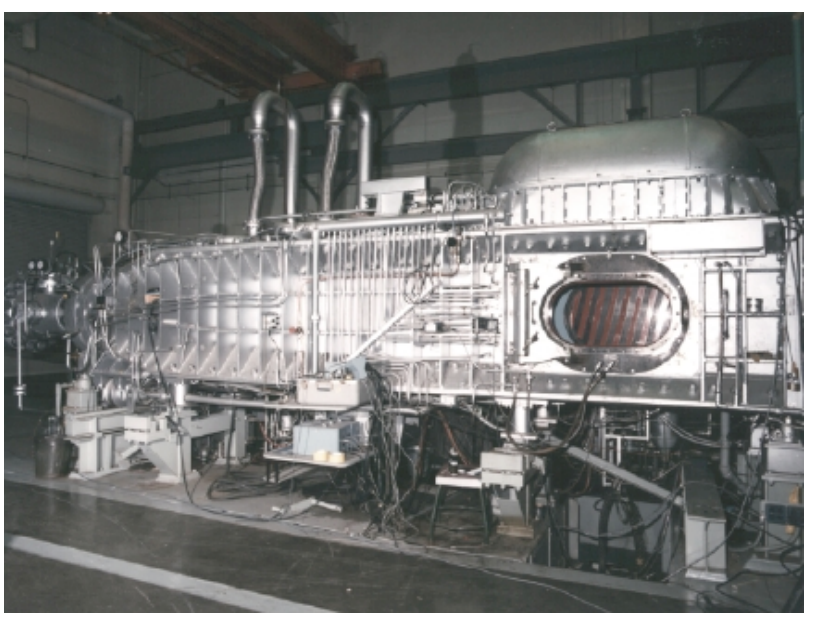

Figure 7. LaRC 31-Inch Mach 10 Air Tunnel

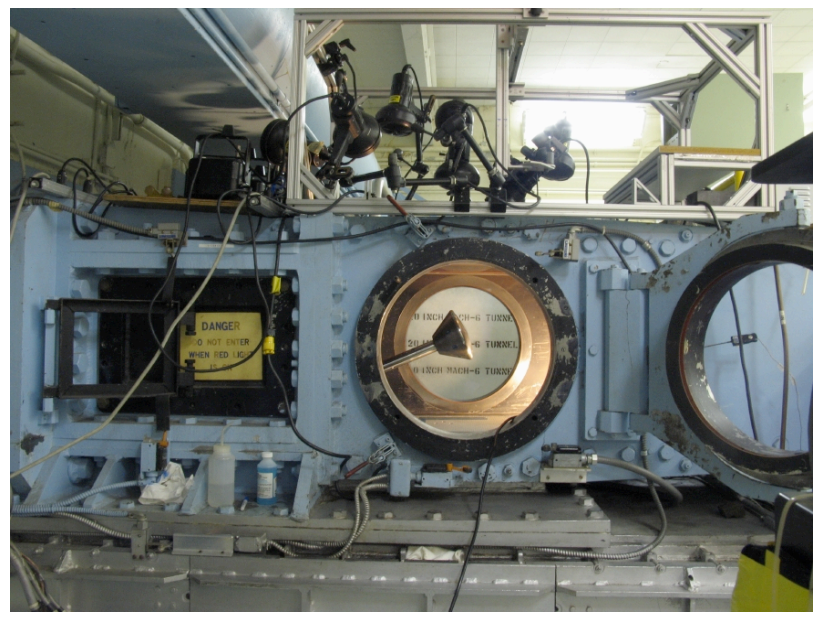

Figure 8. LaRC 20-Inch Mach 6 Air Tunnel

Table 3. Nominal Conditions for LaRC 31-Inch Mach 10 Air Tunnel Test 446

\begin{tabular}{cccccccccccc}
\hline $\begin{array}{c}\alpha \\
(\mathrm{deg})\end{array}$ & $\begin{array}{c}\phi \\
(\mathrm{deg})\end{array}$ & $\begin{array}{c}\mathrm{Re}_{\infty} \\
(1 / \mathrm{ft})\end{array}$ & $\begin{array}{c}\mathrm{Re}_{\infty} \\
(1 / \mathrm{m})\end{array}$ & $\mathrm{M}_{\infty}$ & $\begin{array}{c}\mathrm{P}_{\infty} \\
(\mathrm{Pa})\end{array}$ & $\begin{array}{c}\mathrm{T}_{\infty} \\
(\mathrm{K})\end{array}$ & $\begin{array}{c}\rho_{\infty} \\
\left(\mathrm{kg} / \mathrm{m}^{3}\right)\end{array}$ & $\begin{array}{c}\mathrm{U}_{\infty} \\
(\mathrm{m} / \mathrm{s})\end{array}$ & $\begin{array}{c}\mathrm{H}_{0}-\mathrm{H}_{300 \mathrm{~K}} \\
(\mathrm{~J} / \mathrm{kg})\end{array}$ & $\begin{array}{c}\mathrm{h}_{\mathrm{FR}} \\
(\mathrm{kg} / \mathrm{m} / \mathrm{s})\left(\mathrm{W} / \mathrm{cm}^{2}\right)\end{array}$ \\
\hline $16,20,24$ & 60,240 & $5.27 \mathrm{E}+05$ & $1.73 \mathrm{E}+06$ & 9.68 & 70.2 & 52.9 & $4.63 \mathrm{E}-03$ & 1411.0 & $7.48 \mathrm{E}+05$ & 0.065 & 4.86 \\
$16,20,24$ & 60,240 & $1.02 \mathrm{E}+06$ & $3.36 \mathrm{E}+06$ & 9.81 & 130.1 & 51.7 & $8.77 \mathrm{E}-03$ & 1412.8 & $7.49 \mathrm{E}+05$ & 0.090 & 6.72 \\
$16,20,24$ & 60,240 & $1.38 \mathrm{E}+06$ & $4.53 \mathrm{E}+06$ & 9.87 & 174.6 & 51.7 & $1.18 \mathrm{E}-02$ & 1421.2 & $7.61 \mathrm{E}+05$ & 0.105 & 7.96 \\
$16,20,24$ & 60,240 & $2.00 \mathrm{E}+06$ & $6.55 \mathrm{E}+06$ & 9.96 & 242.0 & 50.6 & $1.67 \mathrm{E}-02$ & 1415.8 & $7.53 \mathrm{E}+05$ & 0.124 & 9.33 \\
\hline
\end{tabular}


Table 4. Nominal Conditions for LaRC 20-Inch Mach 6 Air Tunnel Test 6946

\begin{tabular}{cccccccccccc}
\hline $\begin{array}{c}\alpha \\
(\mathrm{deg})\end{array}$ & $\begin{array}{c}\phi \\
(\mathrm{deg})\end{array}$ & $\begin{array}{c}\mathrm{Re}_{\infty} \\
(1 / \mathrm{ft})\end{array}$ & $\begin{array}{c}\mathrm{Re}_{\infty} \\
(1 / \mathrm{m})\end{array}$ & $\mathrm{M}_{\infty}$ & $\begin{array}{c}\mathrm{P}_{\infty} \\
(\mathrm{Pa})\end{array}$ & $\begin{array}{c}\mathrm{T}_{\infty} \\
(\mathrm{K})\end{array}$ & $\begin{array}{c}\rho_{\infty} \\
\left(\mathrm{kg} / \mathrm{m}^{3}\right)\end{array}$ & $\begin{array}{c}\mathrm{U}_{\infty} \\
(\mathrm{m} / \mathrm{s})\end{array}$ & $\begin{array}{c}\mathrm{H}_{0}-\mathrm{H}_{300 \mathrm{~K}} \\
(\mathrm{~J} / \mathrm{kg})\end{array}$ & $\begin{array}{c}\mathrm{h}_{\mathrm{FR}} \\
\left(\mathrm{kg} / \mathrm{m}^{2} / \mathrm{s}\right)\left(\mathrm{W} / \mathrm{cm}^{2}\right)\end{array}$ \\
\hline $16,20,24$ & 0,180 & $2.10 \mathrm{E}+06$ & $6.89 \mathrm{E}+06$ & 5.96 & 577.2 & 61.9 & $3.25 \mathrm{E}-02$ & 939.5 & $2.03 \mathrm{E}+05$ & 0.106 & 2.15 \\
$16,20,24$ & 0,180 & $5.04 \mathrm{E}+06$ & $1.65 \mathrm{E}+07$ & 6.02 & 1421.0 & 63.2 & $7.84 \mathrm{E}-02$ & 957.5 & $2.21 \mathrm{E}+05$ & 0.169 & 3.73 \\
$16,20,24$ & 0,180 & $7.46 \mathrm{E}+06$ & $2.45 \mathrm{E}+07$ & 6.04 & 2058.0 & 62.5 & $1.15 \mathrm{E}-01$ & 953.6 & $2.17 \mathrm{E}+05$ & 0.203 & 4.40 \\
\hline
\end{tabular}

\section{Data Acquisition, Reduction and Uncertainty}

Heating levels over the model were measured using the two-color, relative intensity, global thermographic phosphor method (Refs. 9, 10). In this method, heat transfer coefficients are determined by assuming a stepfunction in the heat transfer rate upon the start of a run, which corresponds to a parabolic temperature-time history. The model is illuminated by ultraviolet light sources that produce temperature-dependent fluorescence of the phosphor coating and images of the model are taken in the tunnel before and during a run using a three-color, charge-coupled device camera. The IHEAT (Imaging for Hypersonic Experimental Aerothermodynamic Testing) code (Ref. 10) uses calibrations to convert the intensity data from each image pixel to temperatures and then performs the heat transfer computations. Heat transfer distributions from IHEAT are expressed in terms of the ratio $h / h_{\mathrm{FR}}$, where $h_{\mathrm{FR}}$ is the heat transfer coefficient resulting from a Fay-Riddell computation (Ref. 11) for the heat transfer to a sphere with the radius-of-curvature at the nose of the model for a wall temperature of $300 \mathrm{~K}$.

Image data from IHEAT were corrected for optical perspective effects and mapped to a three-dimensional CAD file of the test model that included the recessed and protruding compression pads (Figure 9). This process was performed through a perspective transformation of the original CAD geometry to match the two-dimensional IHEAT image, mapping of the IHEAT data points onto the CAD geometry, and then inversion of the original transformation to produce a corrected, three-dimensional heat transfer map. Information was then extracted from these three-dimensional maps, including heating along the centerline of the model, average heating on the top of each compression pad, and maximum heating levels on each pad (which always occurred at the downstream end or lip of the cavity).

For testing of a blunt-body configuration such as the CEV, an uncertainty estimate for this measurement technique of approximately $\pm 10 \%$ can be made based on Ref. 10. Additional uncertainties are also introduced through the reduction and processing of the data. Because the thermographic phosphor technique is based on an assumption of one-dimensional heat conduction within a model, uncertainty levels in areas with high gradients of lateral/transverse conduction such as wing leading edge, or the case of the CEV around the shoulder between the heat shield and aftbody (crew compartment), can be considerably higher. Analysis of CEV shoulder region data obtained during a test series at AEDC Tunnel 9 (Ref. 12) suggested an additional 10\% uncertainty due to lateral conduction. However, while CEV shoulder data is shown herein, these data are not the primary subject of this report and so this uncertainty will not be considered. Another source of uncertainty is the determination of wind tunnel flow conditions. Since the repeatability and accuracy of flow conditions is very good, the resulting uncertainty in heating measurements was estimated to be only on the order of $\pm 5 \%$. The other major source of uncertainty which must be considered is the transformation and mapping of pixel values from the image data to physical coordinates. This uncertainty is highly problem dependent. On the smooth OML acreage of a CEV model this uncertainty is estimated to be on the order of $\pm 10 \%$. However, in geometrically-complex regions, such as within/around the compression pads or at the heat-shield shoulder, where the scale of such a feature approaches the resolution of the camera optics, this uncertainty could be much higher. For instance, the localized heating spike observed downstream of a recessed pad's cavity or on the leading edge of a protruding pad may be resolved to only a few image pixels and the resulting geometric uncertainty could be in excess of $\pm 25 \%$. Combining these uncertainties in a root-mean square summation gives an uncertainty estimate of $\pm 15 \%$ over the acreage of the model and at least $\pm 27 \%$ around finer geometric features where large heating gradients are present. 


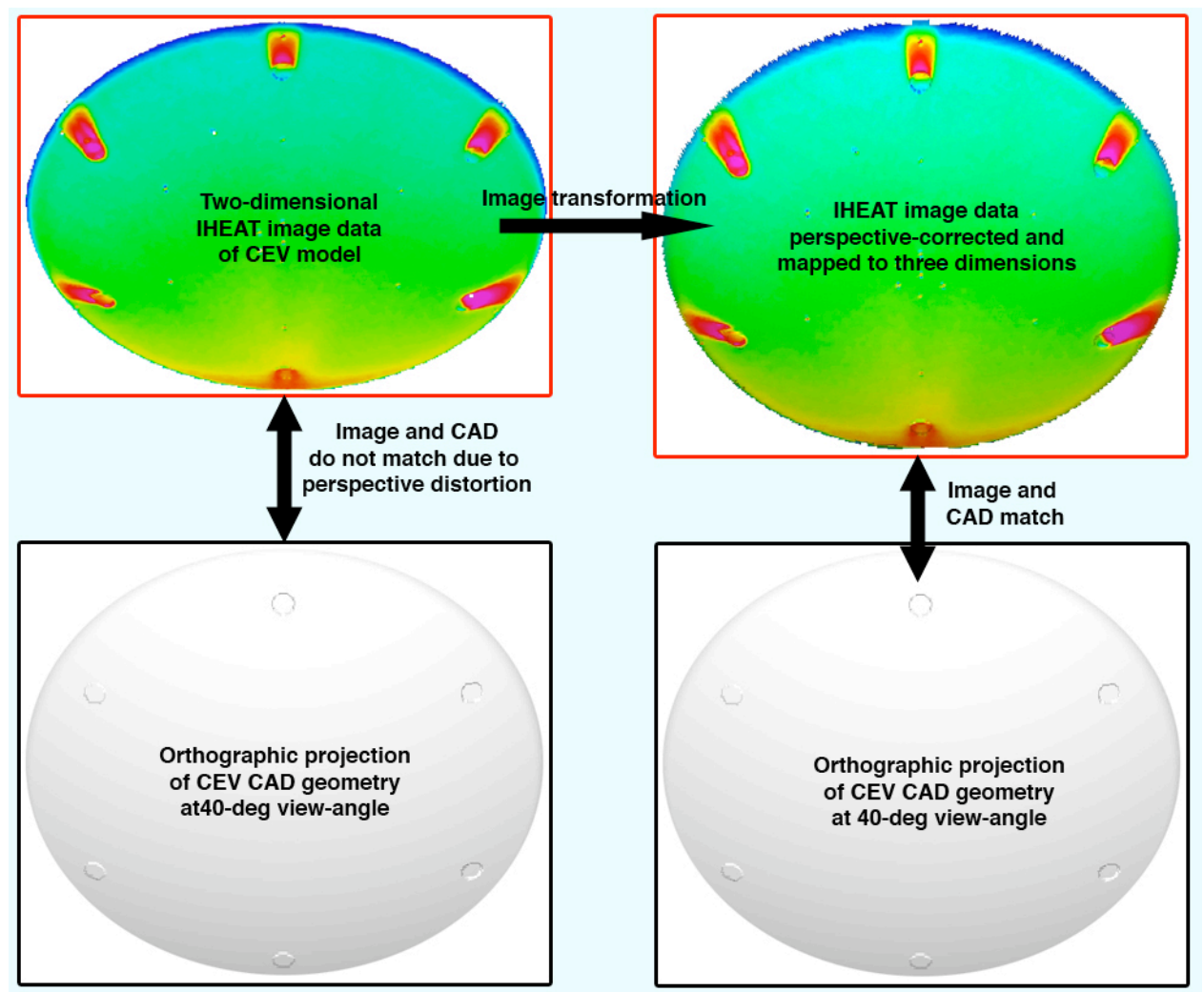

Figure 9. Image transformation and mapping

\section{Computational Method}

Flow field computations at the wind tunnel test conditions were performed using the LAURA (Langley Aerothermodynamic Upwind Relaxation Algorithm) code (Refs. 13 - 14). LAURA is a three-dimensional, finitevolume solver that includes perfect-gas, equilibrium, and non-equilibrium chemistry models. The code can be used to solve the inviscid Euler, viscous thin-layer Navier-Stokes, or full Navier-Stokes equations. In the current study, the thin-layer model was employed; it was concluded in previous studies (Ref. 12) from computations at similar conditions that this model provided accurate results for attached forebody flows. Time integration to steady-state in LAURA is accomplished through point- or line-relaxation schemes. Roe-averaging (Ref. 15) with Harten's entropy fix (Ref. 16) and Yee's Symmetric Total Variation Diminishing limiter (Ref. 17) is used for inviscid fluxes, and a second-order scheme is employed for viscous fluxes. In this study, the perfect-gas air model was used for the wind tunnel predictions. Free stream conditions in these tunnels do not vary significantly from run to run, so the nominal conditions in Table 3 and Table 4 were used with the wall temperature set to a constant $300 \mathrm{~K}$. The use of a constant wall temperature was acceptable because the heat transfer coefficient varies only slightly over the range of wall temperatures produced in these facilities. All computations were performed on a smooth (no compression pad) grid of the CEV OML in order to obtain baseline heating levels to compare against the compression pad heating data and boundary-layer properties for correlation of the experimental data.

\section{Results and Analysis}

\section{A. Global Effects on Heating}

Sample global heating images obtained from the Mach 10 and Mach 6 tunnel tests are given in Figure 10 and Figure 11. Close-up views of the heating at pads \#1 and \#2 (numbered clockwise from the top) are shown in Figure 12 and Figure 13. Because of optical access differences in the two facilities, the viewing angle that could be obtained in the Mach 10 test was more oblique than that in the Mach 6 tests and thus the wind side (bottom) of the model could not be sufficiently illuminated to obtain high quality data. Therefore the wind-side centerline cavity data from the Mach 10 tests were not included in the final correlation data set. Additionally, the high stagnation 
temperatures in the 31-Inch Mach 10 Air Tunnel produced surface temperatures on the test model that sometimes exceeded the calibration range of the thermographic phosphor system. These excessive temperatures occurred on the downstream lip of, and downstream of, the recessed cavities and on the leading edges of the protruding pads at the higher free stream Reynolds numbers $\left(\operatorname{Re}_{\infty}=1.38 \times 10^{6} / \mathrm{ft}\right.$ and $\left.\operatorname{Re}_{\infty}=2.00 \times 10^{6} / \mathrm{ft}\right)$ These data were also excluded from the final data set. Finally, jagged edges at the bottom (wind-side) of each image are artifacts from the mapping of image data points from surfaces that are nearly parallel to the line of sight of the camera.

Laminar flow was produced over the acreage of the vehicle at all test conditions except at the highest Mach 6 test Reynolds number $\left(\operatorname{Re}_{\infty}=7.46 \times 10^{6} / \mathrm{ft}\right)$ where transitional flow was generated on the leeside of the heat-shield upstream of the cavities; these transitional data were excluded from the augmentation correlations. Heating augmentation above the upstream levels was observed downstream of the pads for all conditions; however, it was not apparent from the data if this augmentation represented boundary-layer transition or was due only to perturbations of the flow streamlines due to the presence of the pads.

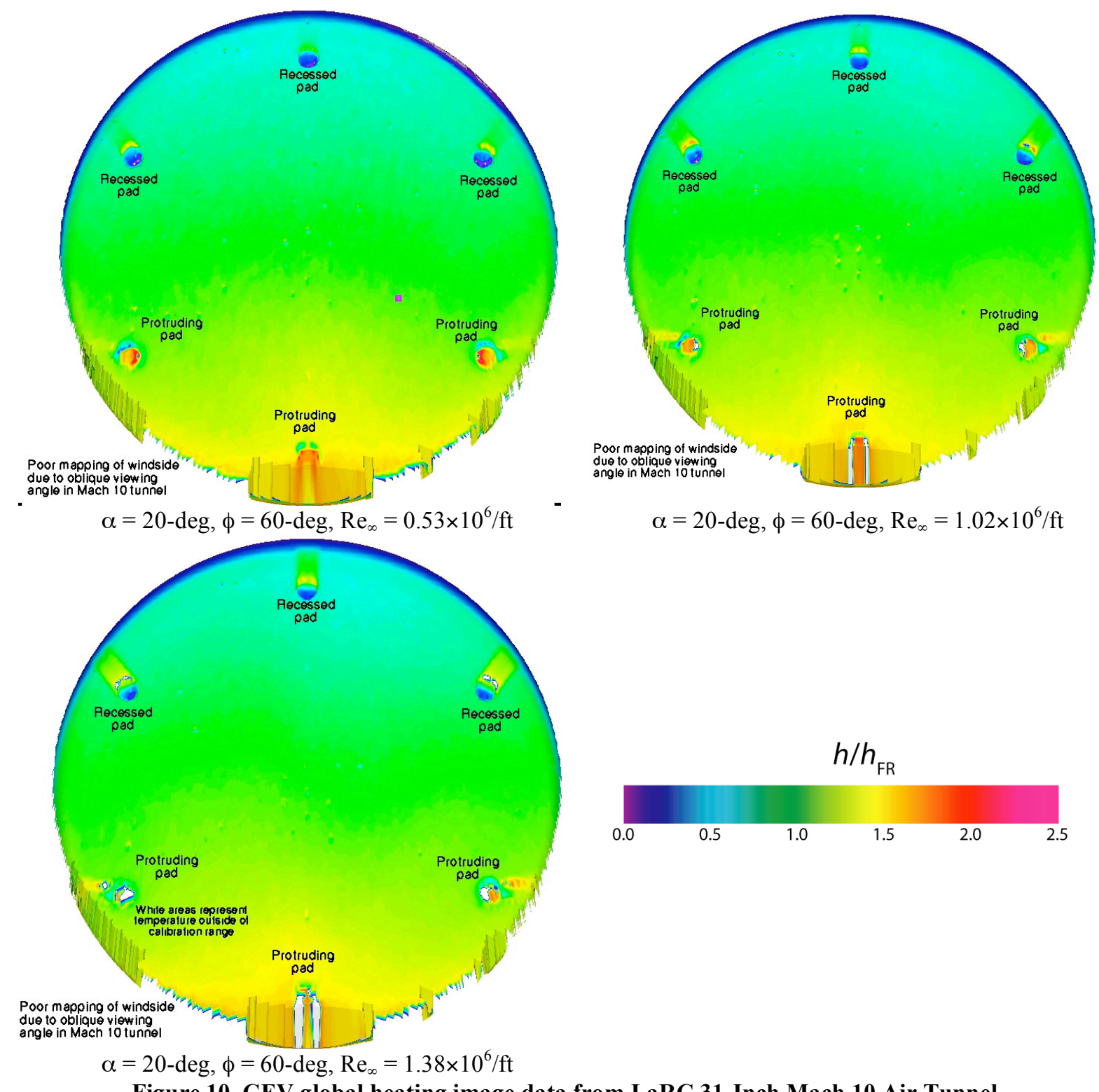

Figure 10. CEV global heating image data from LaRC 31-Inch Mach 10 Air Tunnel 


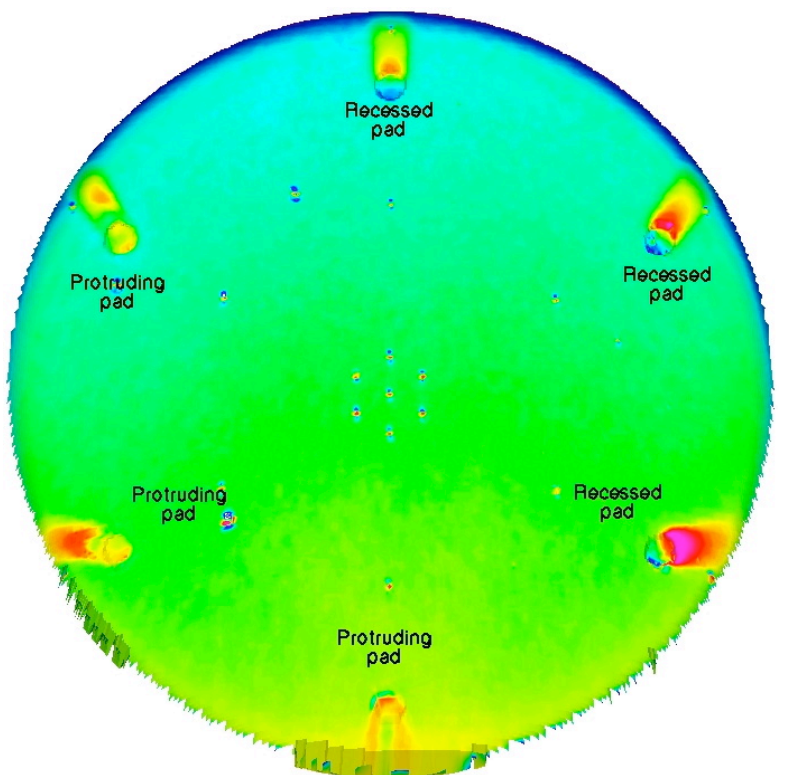

$\alpha=20-\mathrm{deg}, \phi=0-\mathrm{deg}, \mathrm{Re}_{\infty}=2.10 \times 10^{6} / \mathrm{ft}$

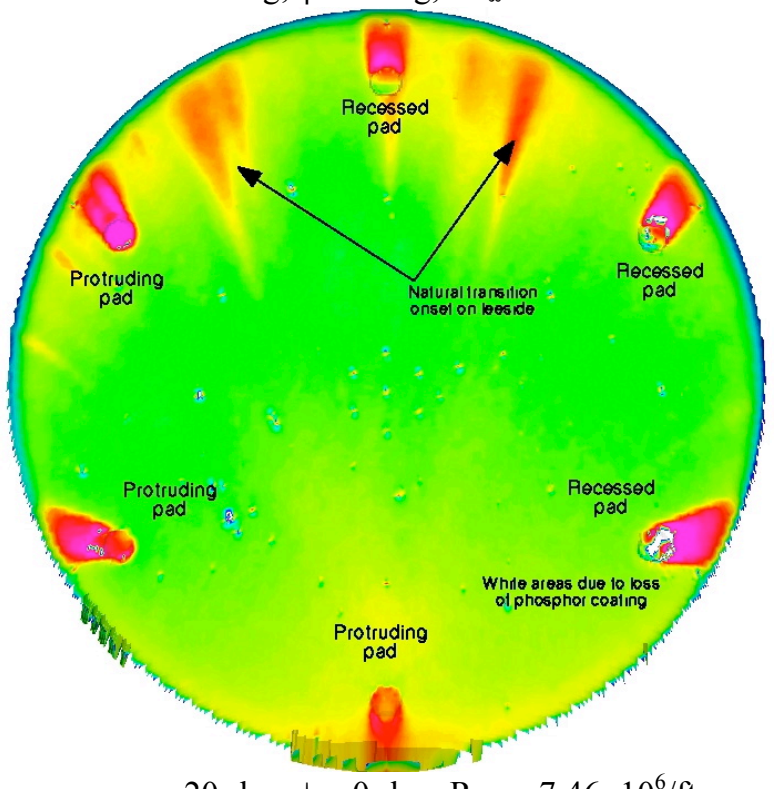

$\alpha=20-\mathrm{deg}, \phi=0$-deg, $\mathrm{Re}_{\infty}=7.46 \times 10^{6} / \mathrm{ft}$

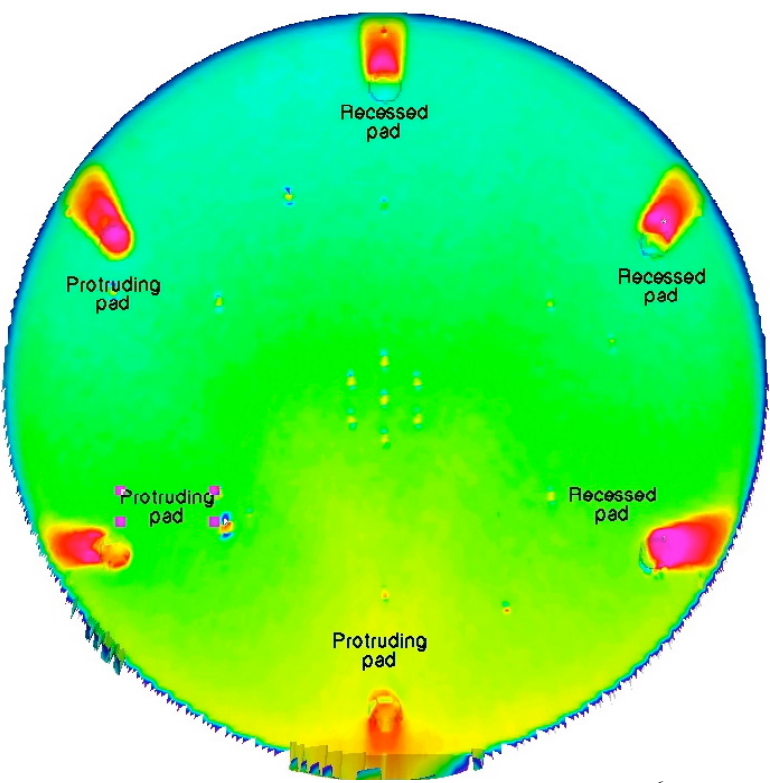

$\alpha=20$-deg, $\phi=0$-deg, $\operatorname{Re}_{\infty}=5.04 \times 10^{6} / \mathrm{ft}$

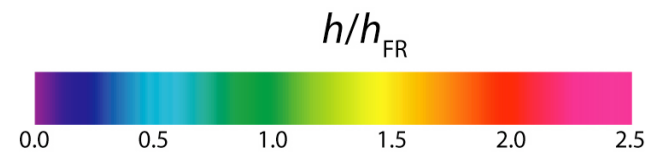

Figure 11. CEV global heating image data from LaRC 20-Inch Mach 6 Air Tunnel 

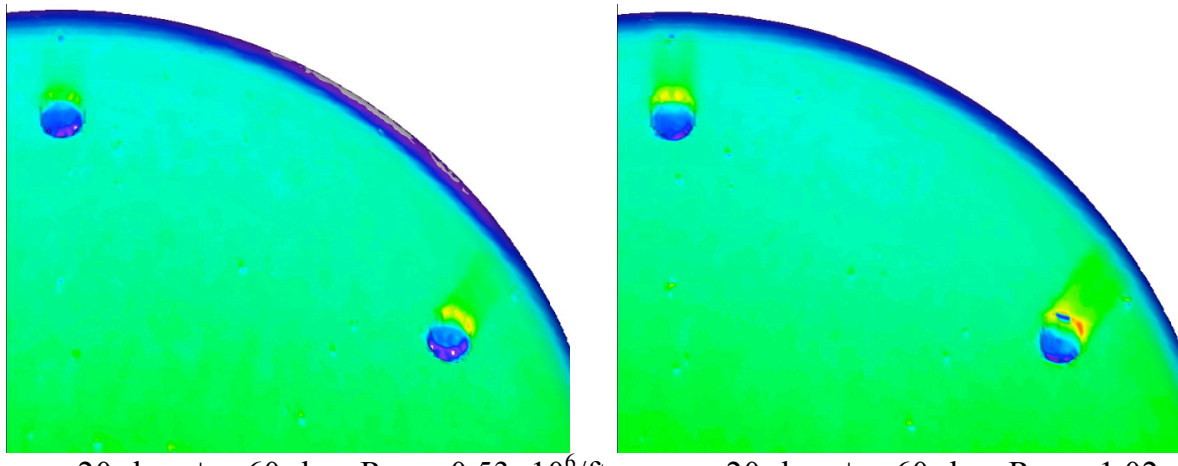

$\alpha=20$-deg, $\phi=60-$ deg, $\operatorname{Re}_{\infty}=0.53 \times 10^{6} / \mathrm{ft}$ $\alpha=20$-deg, $\phi=60$-deg, $\operatorname{Re}_{\infty}=1.02 \times 10^{6} / \mathrm{ft}$
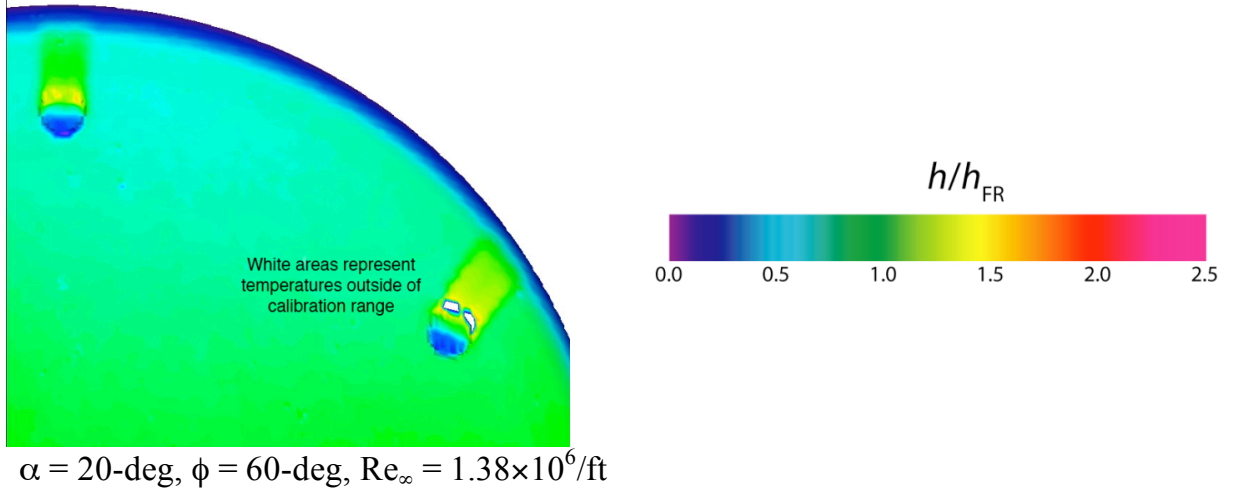

Figure 12. Close-up views of $\mathrm{CEV}$ cavity heating image data from LaRC 31-Inch Mach 10 Air Tunnel
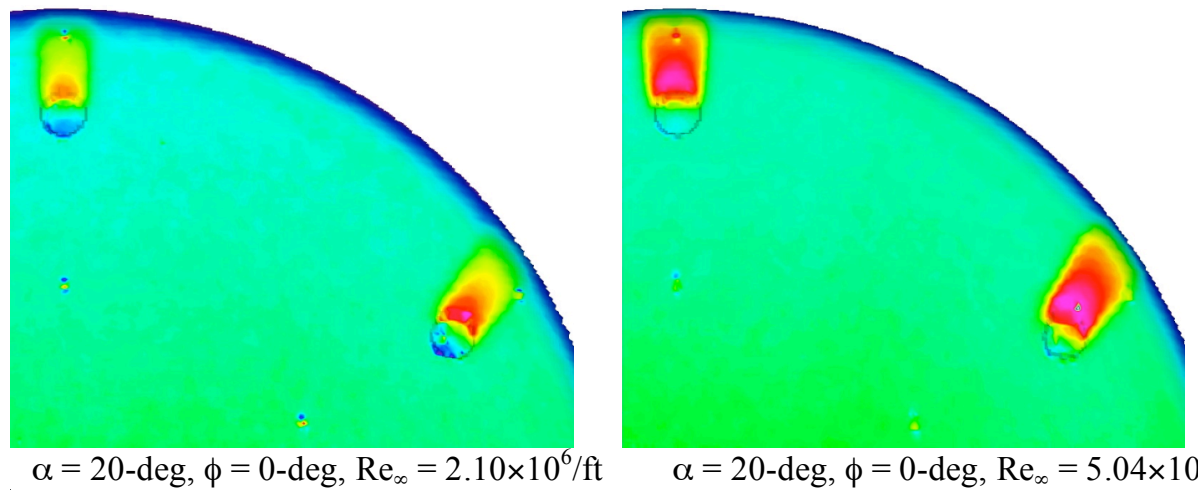

$\alpha=20$-deg, $\phi=0$-deg, $\operatorname{Re}_{\infty}=2.10 \times 10^{6} / \mathrm{ft}$
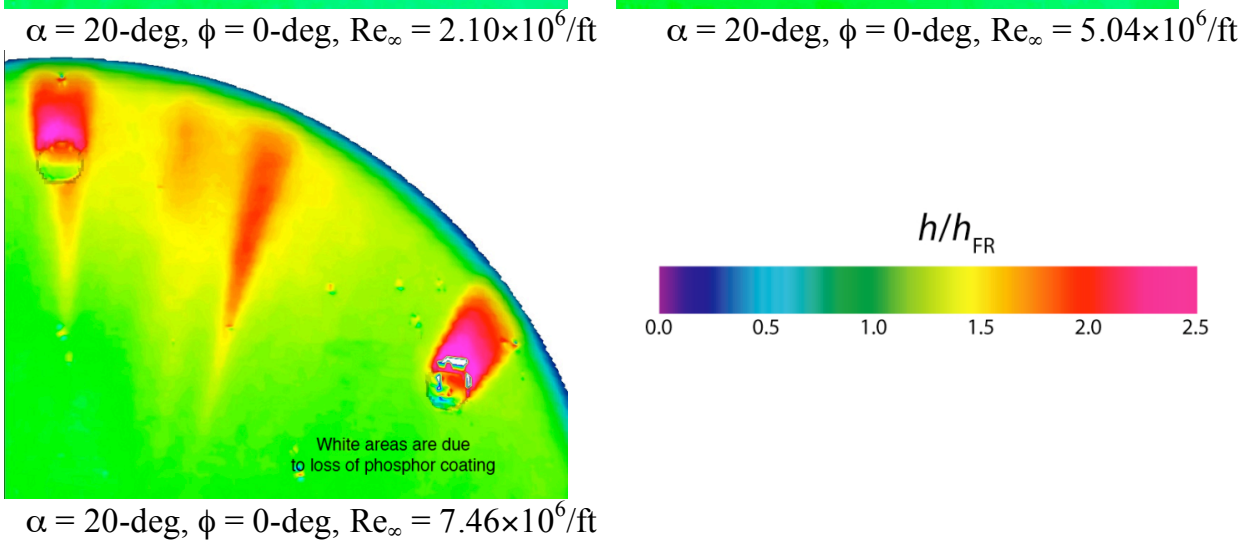

Figure 13. Close-up views of $\mathrm{CEV}$ cavity heating image data from LaRC 20-Inch Mach 6 Air Tunnel 


\section{B. Centerline Comparisons with Predictions}

Sample comparisons of experimental centerline heating data with the laminar, smooth OML predictions in the leeside centerline pad region for cases with both recessed and protruding pads are shown in Figure 14 to Figure 17 $\left(z / R_{B}\right.$ in these plots is the normalized distance along the centerline pitch plane). Laminar predictions upstream of the pads matched the data to well within the estimated $\pm 15 \%$ acreage uncertainty except at the transitional Mach $6, \operatorname{Re}_{\infty}$ $=7.46 \times 10^{6} / \mathrm{ft}$ condition.

For the recessed pad Mach 10 cases, the heating levels within the cavity dropped to near zero at the start of the cavity and rose to approximately the smooth OML levels at the downstream end of the cavity for all conditions except the highest free-stream Reynolds number. For the Mach 6 recessed pad cases, the heating decrease at the beginning of the cavity was smaller and the heating levels at the downstream end of the cavity exceeded those of the smooth OML by up to $100 \%$. For both Mach 6 and Mach 10 conditions, a large heating increase was also measured at the downstream lip of the cavity with levels between $50 \%$ and $300 \%$ higher than the smooth OML predictions.

For the protruding pad cases, heating augmentations of $200 \%$ to $300 \%$ were observed on the pads with the highest values at the leading edge of the pads. Downstream of the pads, heating levels decreased sharply but then began to rise again due to the presence of horseshoe vortices immediately behind the protruding pads.

\section{Correlation of Compression Pad Heating Data}

In order to assist in the mechanical-thermal design of the compression pads on the CEV vehicle, it is desirable to correlate the compression pad heating data in terms of the pad geometry and local flow conditions. Two correlations were developed for the recessed pad data: one for the ratio of average heating over the compression pad surface to the predicted, laminar, smooth OML heating; and one for the ratio of the maximum compression pad heating (always at the downstream end of the pad and cavity wall) to the predicted, laminar, smooth OML heating. It is currently expected that the compression pads will not protrude above the CEV OML, so no correlations of the protruding pad data have yet been developed.

All heating data from both CEV-1X and CEV-2X model testing in the LaRC 20-Inch Mach 6 and 31-Inch Mach 10 Air Tunnels were included in the correlation database except as noted previously and the leeside transitional data at the Mach $6, R e_{\infty}=7.46 \times 10^{6} / \mathrm{ft}$ condition. Additional cavity data were added from previous testing of the MSL and Genesis models; however, not all of the available MSL and Genesis data were used. Because the diameters of the cavities on these models were smaller than those on the CEV models, the resolution of the images was not sufficient to discern details at all cavities except for the two largest cavities on the MSL models and the four largest cavities on the Genesis models. Thus, the data from these smaller cavities was not considered. Additionally, much of the wind-side centerline cavity data from these models were omitted from the database because of the poor viewing angle of these cavities.

The relevant correlation parameters for compression pad heating augmentation were found to include the cavity diameter $\left(D_{\mathrm{PAD}}\right)$ and height $\left(H_{\mathrm{PAD}}\right)$, the local boundary layer height $(\delta)$, and the boundary layer momentum-thickness Reynolds number $\left(R e_{\theta}\right)$. Inclusion of the local boundary layer edge Mach number $\left(M_{\mathrm{e}}\right)$, which varied between 0.01 and 1.08, was not found to increase the accuracy of the correlations. Various permutations of these and other variables were examined until finally a multi-variable power-law equation of the following form was determined to provide the best correlations for the average and maximum heating augment factors:

$$
A F=C 1 \times\left(\mathrm{Re}_{\theta}\right)^{C 2} \times\left(D_{P A D} / H_{P A D}\right)^{C 3} \times\left(H_{P A D} / \delta\right)^{C 4}
$$

The average and maximum recessed compression pad heating augmentation correlations are presented in Figure 18 and Figure 19. The data included in these correlations span a range of momentum-thickness Reynolds numbers of $R e_{\theta}=20$ to 275 , cavity aspect ratios of $\left(D_{\mathrm{PAD}} / H_{\mathrm{PAD}}\right)=2.9$ to 15.3 , and normalized cavity depths of $\left(H_{\mathrm{PAD}} / \delta\right)=$ 0.35 to 6.3 . For these parameters, average augmentation factors varied from 0.5 to 2.0 (the cavity floor experiences lower average heating than the OML at some conditions) and maximum augmentation factors varied from 1.0 to 4.0. These correlations should be regarded as preliminary since testing of additional CEV compression pad models is planned (with shallower cavities and smaller diameters) to expand the database. Also, these correlations are only valid if the upstream flow is laminar; additional testing is planned to obtain data at transitional and turbulent conditions, and it is expected that such conditions would produce different correlations from those presented herein.

\section{Summary and Conclusions}

The effects of recessed and protruding compression pads on the aeroheating environment of the CEV heat-shield has been studied through testing at perfect-gas Mach 6 and Mach 10 conditions. Laminar, smooth-body predictions

11

American Institute of Aeronautics and Astronautics 
were found to agree well with the data upstream of the compression pads, while heating augmentation above the predicted smooth OML levels was observed at and downstream of the pads. Average heating augmentation levels on the recessed pads varied from 0.5 to 2.5 while the maximum augmentation levels varied between 1.0 and 4.0. Data from these tests and additional data from previous tests on the MSL and Genesis configurations were correlated in terms of compression pad geometry and boundary-layer parameters. These results can be used in the design of the compression pad for the actual flight vehicles (CEV or any blunt body configuration) as well as for validation of CFD predictions.

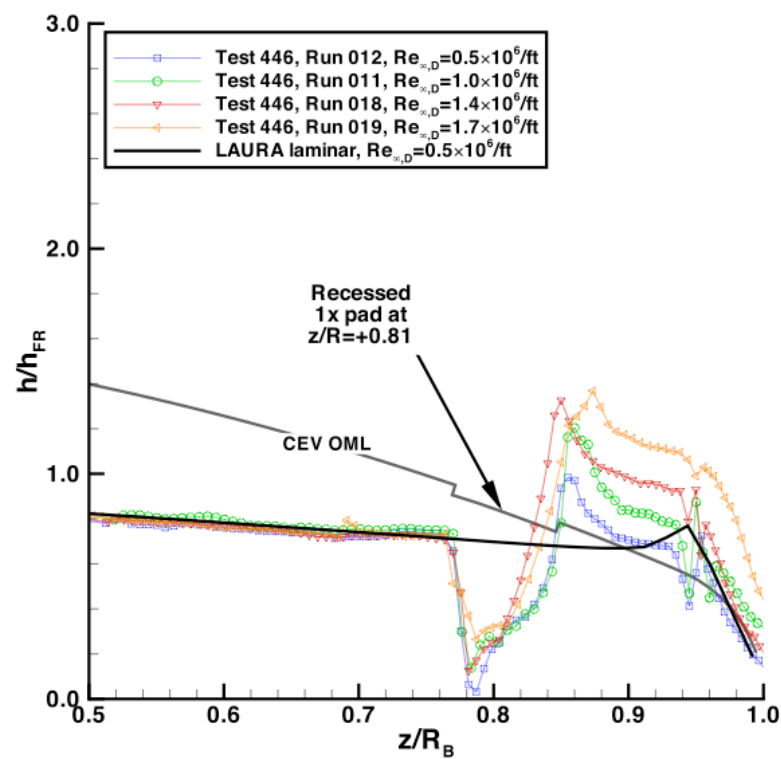

Figure 14. CEV leeside centerline recessed pad heating for $\alpha=20-d e g, \phi=60-d e g$, LaRC 31-Inch Mach 10 Air Tunnel

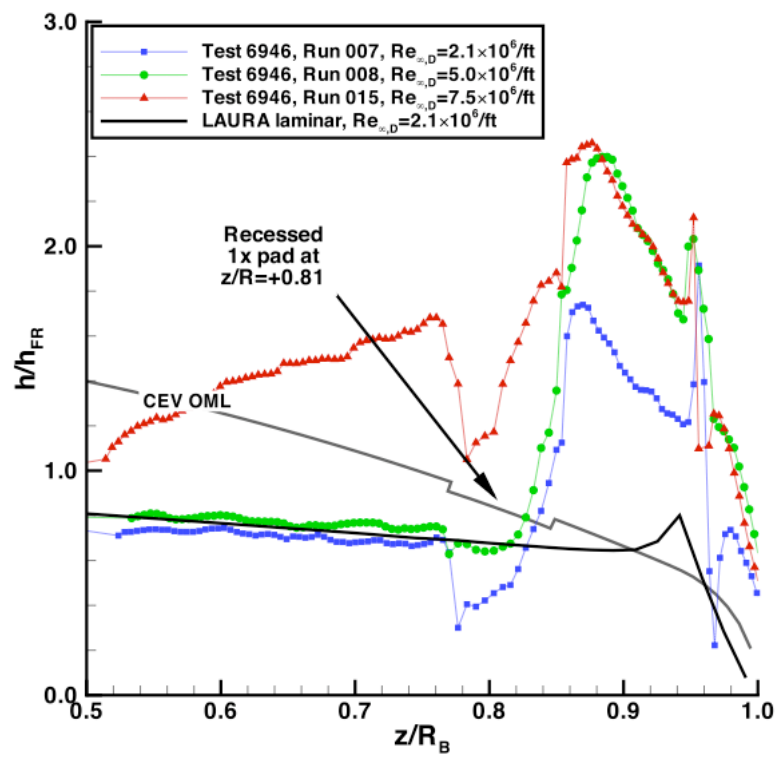

Figure 16. CEV leeside centerline recessed pad for $\alpha$ $=$ 20-deg, $\phi=0$-deg, LaRC 20-Inch Mach 6 Air Tunnel

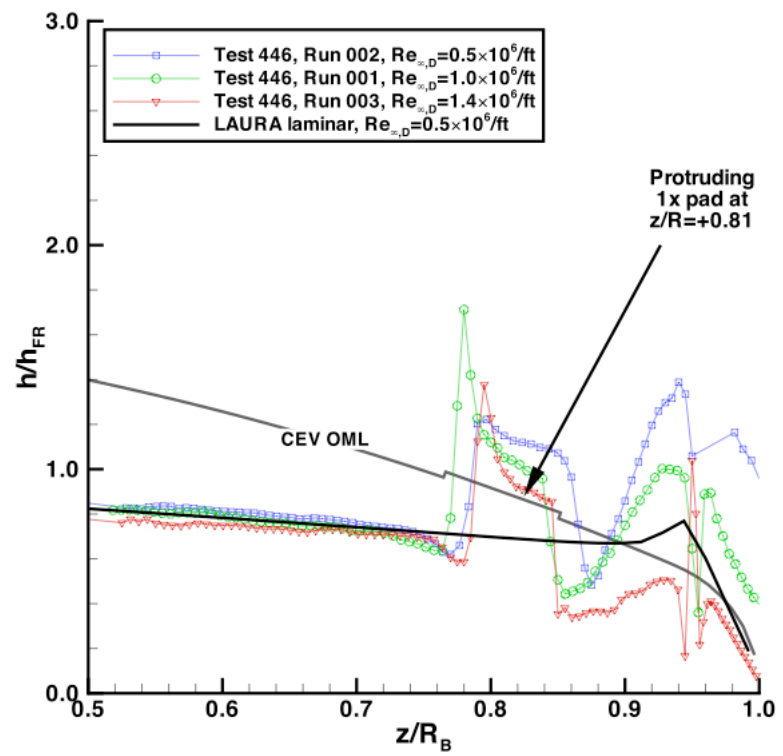

Figure 15. CEV leeside centerline protruding pad heating for $\alpha=20-\mathrm{deg}, \phi=240-\mathrm{deg}$, LaRC 31-Inch Mach 10 Air Tunnel

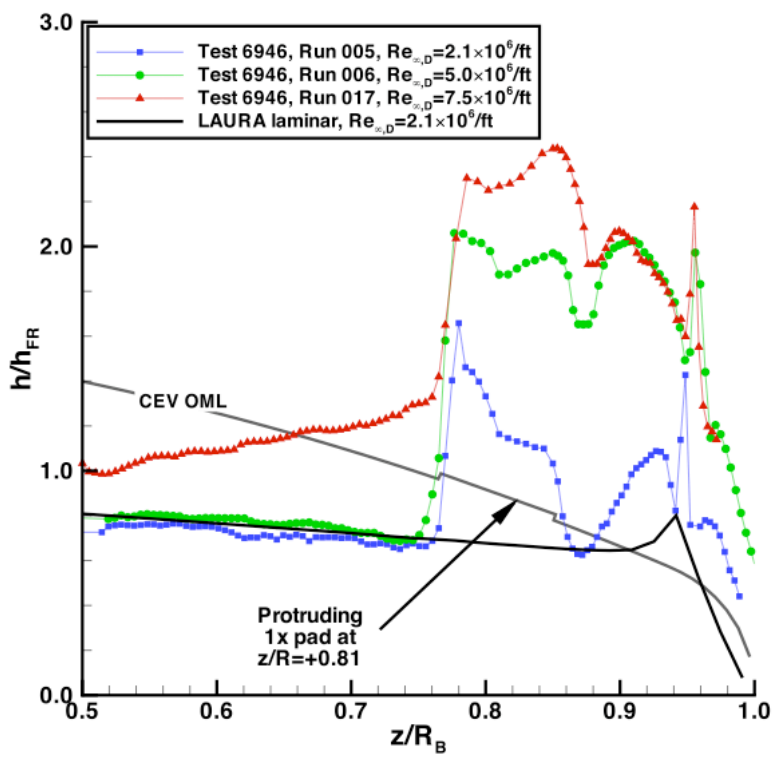

Figure 17. CEV leeside centerline protruding pad for $\alpha=$ 20-deg, $\phi=180$-deg, LaRC 20-Inch Mach 6 Air Tunnel

12

American Institute of Aeronautics and Astronautics 


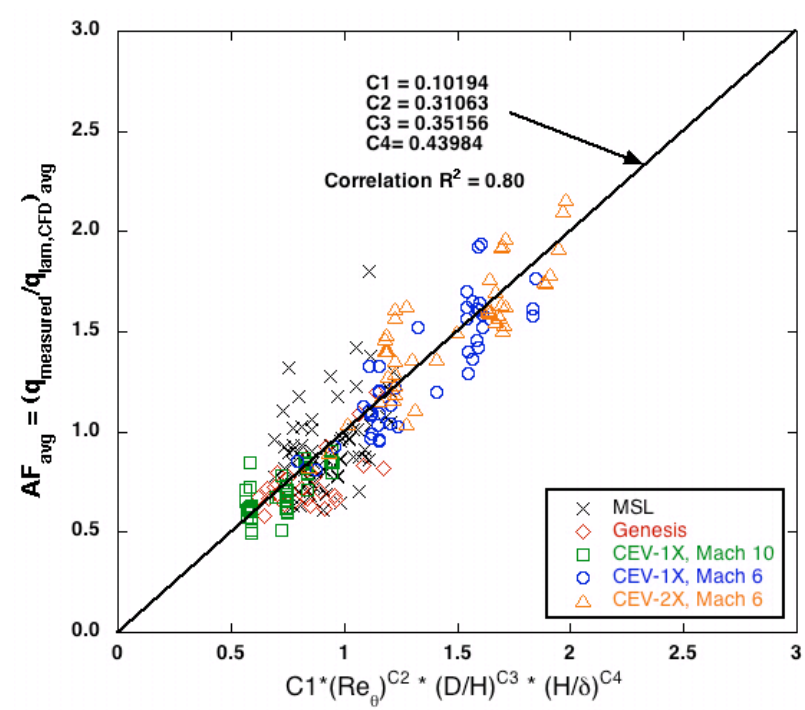

Figure 18. Correlation for average recessed pad heating augmentation factor

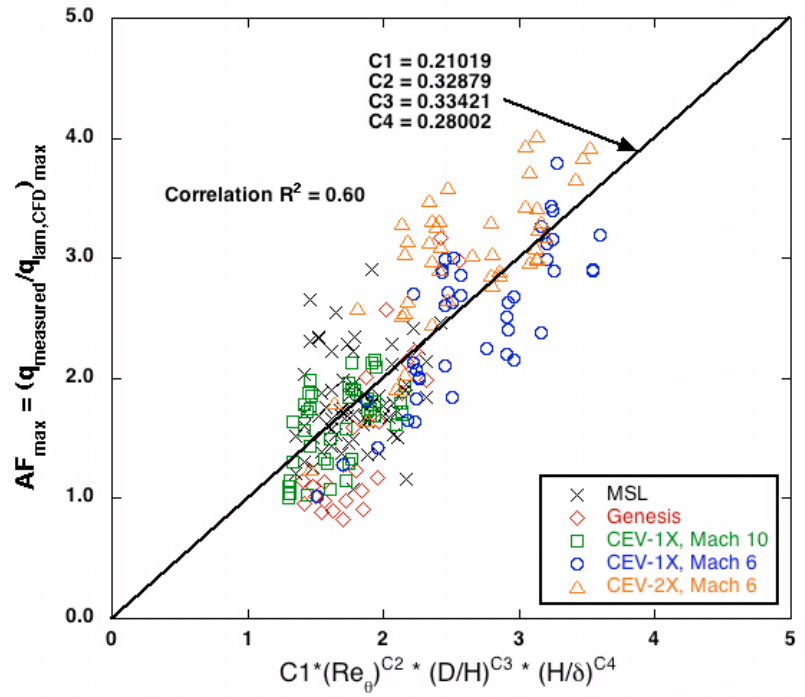

Figure 19. Correlation for maximum recessed pad heating augmentation factor

\section{References}

1 “NASA’s Exploration Systems Architecture Study, Final Report," NASA TM-2005-214062, November, 2005.

${ }^{2}$ Cheatwood, F. M., Merski, N. R., Riley, C. J., and Mitcheltree, R. A., "Aerothermodynamic Environment Definition for the Genesis Sample Return Capsule," AIAA Paper 2001-2889, 35 ${ }^{\text {th }}$ AIAA Thermophysics Conference, Anaheim, CA. June 11-14, 2001.

${ }^{3}$ Liechty, D. S., Hollis, B. R., and Edquist, K. T., "Mars Science Laboratory Experimental Aerothermodynamics with Effects of Cavities and Control Surfaces," Journal of Spacecraft and Rockets, Vol. 43, No. 2, March-April 2006, pp. 340-353.

${ }^{4}$ Hollis, B. R., and Liechty, D. S., "Transition Due to Heat-Shield Cavities on a Mars Entry Vehicle," Journal of Spacecraft and Rockets, Vol. 43, No. 2, March-April 2006, pp. 354-366.

${ }^{5}$ Hollis, B. R. and Liechty, D. S., "Correlations for Boundary-Layer Transition on Mars Science Laboratory Entry Vehicle Due to Heat-Shield Cavities," NASA TP-2008-215317, June 2008.

${ }^{6}$ Buck, G. M., "Rapid Model Fabrication and Testing for Aerospace Vehicles," AIAA Paper 2000-0826, 38 ${ }^{\text {th }}$ AIAA Aerospace Sciences Meeting and Exhibit, Reno, NV, January 10-13, 2000.

${ }^{7}$ Liechty, D. S., "Aerothermodynamic Testing of Protuberances and Penetrations on the NASA Crew Exploration Vehicle Heat Shield," AIAA Paper 2008-1240, 46 ${ }^{\text {th }}$ AIAA Aerospace Sciences Meeting and Exhibit, Reno, NV, January 7-10, 2008.

${ }^{8}$ Micol, J. R. "Langley Aerothermodynamic Facilities Complex: Enhancements and Testing Capabilities," AIAA Paper 98-0147, $36^{\text {th }}$ AIAA Aerospace Sciences Meeting and Exhibit, Reno, NV, January 12-15, 1998.

${ }^{9}$ Buck, G. M., "Surface Temperature/Heat Transfer Measurement Using a Quantitative Phosphor Thermography System,” AIAA Paper 91-0064, January 1991.

${ }^{10}$ Merski, N. R., "Global Aeroheating Wind-Tunnel Measurements Using Improved Two-Color Phosphor Thermography Methods, Journal of Spacecraft and Rockets, Vol. 36, No. 2, pp. 160-170, March-April 1999.

${ }^{11}$ Fay, J. A., and Riddell, F. R., "Theory of Stagnation Point Heat Transfer in Dissociated Air," Journal of Aeronautical Sciences, Vol. 25, No. 2., pp. 73-85, February 1958.

${ }^{12}$ Hollis, B. R., Berger, K. T., Horvath, T. J., Coblish, J. J., Norris, J. T., Lillard, R. P, and Kirk, B. S., "Aeroheating Testing and Predictions for Project Orion CEV at Turbulent Conditions," AIAA Paper 2008-1226, 46th AIAA Aerospace Sciences Meeting and Exhibit, Reno, NV, Jan. 7-10, 2008.

${ }^{13}$ Gnoffo, P. A., “An Upwind-Biased, Point-Implicit Algorithm for Viscous, Compressible Perfect-Gas Flows,” NASA TP-2953, February 1990.

${ }^{14}$ Cheatwood, F. M., and Gnoffo, P. A., “User's Manual for the Langley Aerothermodynamic Upwind Relaxation Algorithm (LAURA)," NASA TM 4674, April, 1996.

${ }^{15}$ Roe, P. L., "Approximate Riemann Solvers, Parameter Vectors and Difference Schemes," Journal of Computational Physics, Vol. 43, No. 2, 1981, pp. 357-372.

${ }^{16}$ Harten, A., "High Resolution Schemes for Hyperbolic Conservation Laws," Journal of Computational Physics, Vol. 49, No. 3, 1983, pp. 357-393.

${ }^{17}$ Yee, H. C., "On Symmetric and Upwind TVD Schemes," NASA TM 88325, 1990. 